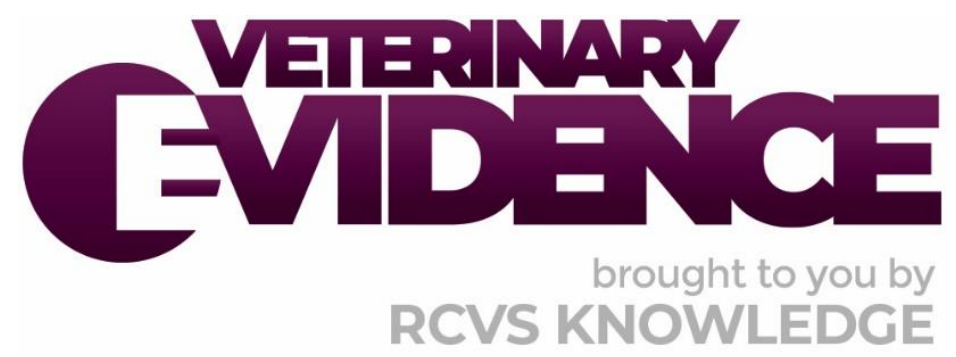

\title{
Evaluating the reliability of computed tomography for the diagnosis of intervertebral disc extrusion in dogs
}

\section{A Knowledge Summary by}

Chloe Smith BVSc (Dist) PGDip VCP MRCVS ${ }^{1^{*}}$

\footnotetext{
1 Langford Veterinary Services, Langford House, Langford, BS40 5DU, UK

* Corresponding Author (cs13407@bristol.ac.uk)
}

ISSN: 2396-9776

Published: 01 Dec 2021

in: The Veterinary Evidence journal Vol 6, Issue 4

DOI: https://doi.org/10.18849/ve.v6i4.384

Reviewed by: Elizabeth Baines (MA VetMB DVR DipECVDI

FHEA MRCVS) and Tom Shaw (BVetMed MA MRCVS DipECVN)

Next Review Date: 08 Dec 2022 


\section{KNOWLEDGE SUMMARY}

\section{PICO question}

In dogs with an acute thoracolumbar myelopathy, is non-contrast computed tomography (CT) a reliable method for the diagnosis of intervertebral disc extrusion, compared to magnetic resonance imaging (MRI)?

\section{Clinical bottom line}

\section{Category of research question}

\section{Diagnosis}

\section{The number and type of study designs reviewed}

Four papers were critically reviewed. Two were retrospective, cross-sectional studies, and two were prospective, observational cohort studies

\section{Strength of evidence}

Moderate

\section{Outcomes reported}

The current literature suggests that $\mathrm{CT}$ is often sufficient for the diagnosis of thoracolumbar intervertebral disc extrusion, with MRI superior to CT for lesion characterisation. Non-contrast CT is likely sufficient for the diagnosis and surgical planning for intervertebral disc disease in Dachshunds. However, MRI is recommended for diagnosis and surgical planning of thoracolumbar intervertebral disc disease in non-Dachshund breeds

\section{Conclusion}

Computed tomography is often sufficient for the diagnosis of thoracolumbar intervertebral disc extrusion. However, MRI is superior to CT for lesion characterisation and it is therefore recommended to use MRI for cases requiring surgical planning. Computed tomography is likely sufficient for the diagnosis and surgical planning of intervertebral disc disease in Dachshunds

Regard for the reason of diagnostics performed (e.g. surgical planning) and the likelihood of other differential diagnoses (e.g. spinal neoplasms) should be taken before deciding to use one imaging modality over the other. Consideration into the risks associated with anaesthetising an animal with a spinal cord lesion, the ability of the practitioner to accurately localise the myelopathy and interpret the results, should be taken before pursuing diagnostics in these cases

\section{How to apply this evidence in practice}

The application of evidence into practice should take into account multiple factors, not limited to: individual clinical expertise, patient's circumstances and owners' values, country, location or clinic where you work, the individual case in front of you, the availability of therapies and resources.

Knowledge Summaries are a resource to help reinforce or inform decision making. They do not override the responsibility or judgement of the practitioner to do what is best for the animal in their care. 


\section{Clinical Scenario}

You are presented with a Dachshund, with acute onset paraplegia, that you suspect has an intervertebral disc extrusion between the T3 and L3 spinal cord segments. You are confident performing a hemilaminectomy procedure and have access to both computed tomography (CT) and magnetic resonance imaging (MRI). You therefore want to know if $\mathrm{CT}$, in comparison to MRI, is a reliable modality for the diagnosis and surgical planning of thoracolumbar disc extrusions in dogs.

\section{The evidence}

Of the four papers reviewed, two were prospective and two were retrospective studies in nature. The strength of evidence for each paper is considered moderate, with the absence of a systematic review or meta-analysis for this topic.

Paper one (Cooper et al., 2014) is the only study to directly compare the sensitivity of MRI versus CT in the diagnosis of thoracolumbar intervertebral disc disease in dogs and this evidence was therefore considered stronger when reaching a clinical bottom line. However, the other three papers all provide insight into the use of both imaging modalities in the diagnosis of thoracolumbar myelopathies and provide evidence to concur with the conclusions drawn by Cooper et al. (2014).

\section{Summary of the evidence}

\begin{tabular}{|c|c|}
\hline Cooper et al. (2014) & \\
\hline Population: & Dogs with neurological signs localised to T3-S1. \\
\hline Sample size: & 44 dogs (35 chondrodystrophic, nine other breeds). \\
\hline Intervention details: & All dogs had both a non-contrast CT and an MRI. \\
\hline Study design: & Observational cohort study. \\
\hline Outcome studied: & $\begin{array}{l}\text { - Sensitivity of non-contrast CT versus MRI for detecting } \\
\text { intervertebral disc herniation. } \\
\text { - Accuracy of non-contrast CT versus MRI for lesion } \\
\text { localisation and lateralisation. }\end{array}$ \\
\hline $\begin{array}{l}\text { Main findings: } \\
\text { (relevant to PICO question): }\end{array}$ & 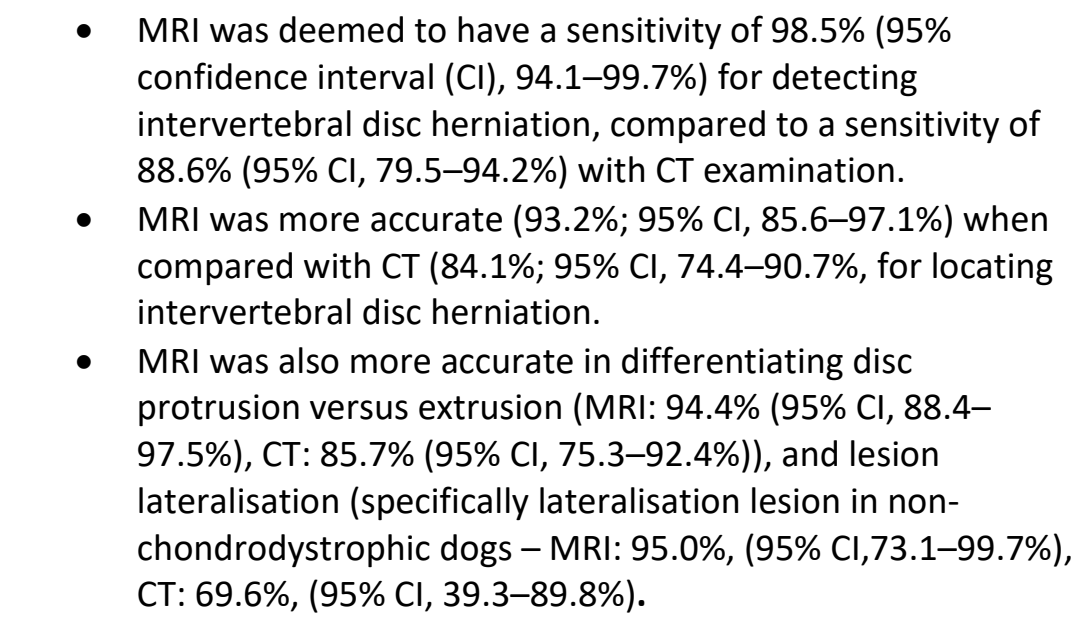 \\
\hline Limitations: & $\begin{array}{l}\text { - All measurements have not been adjusted for prevalence } \\
\text { and therefore specificity could not be evaluated. } \\
\text { - Surgery was used as the confirmatory technique for the } \\
\text { characterisation of the intervertebral disc herniation, risking } \\
\text { bias and restricting the areas that can be investigated to } \\
\text { confirm disc herniation. }\end{array}$ \\
\hline
\end{tabular}




\begin{tabular}{|l|l|}
\hline & $\begin{array}{l}\text { - } \\
\text { and therefore an inability to fully compare MRI to CT for } \\
\text { lesion characterisation. }\end{array}$ \\
\hline
\end{tabular}

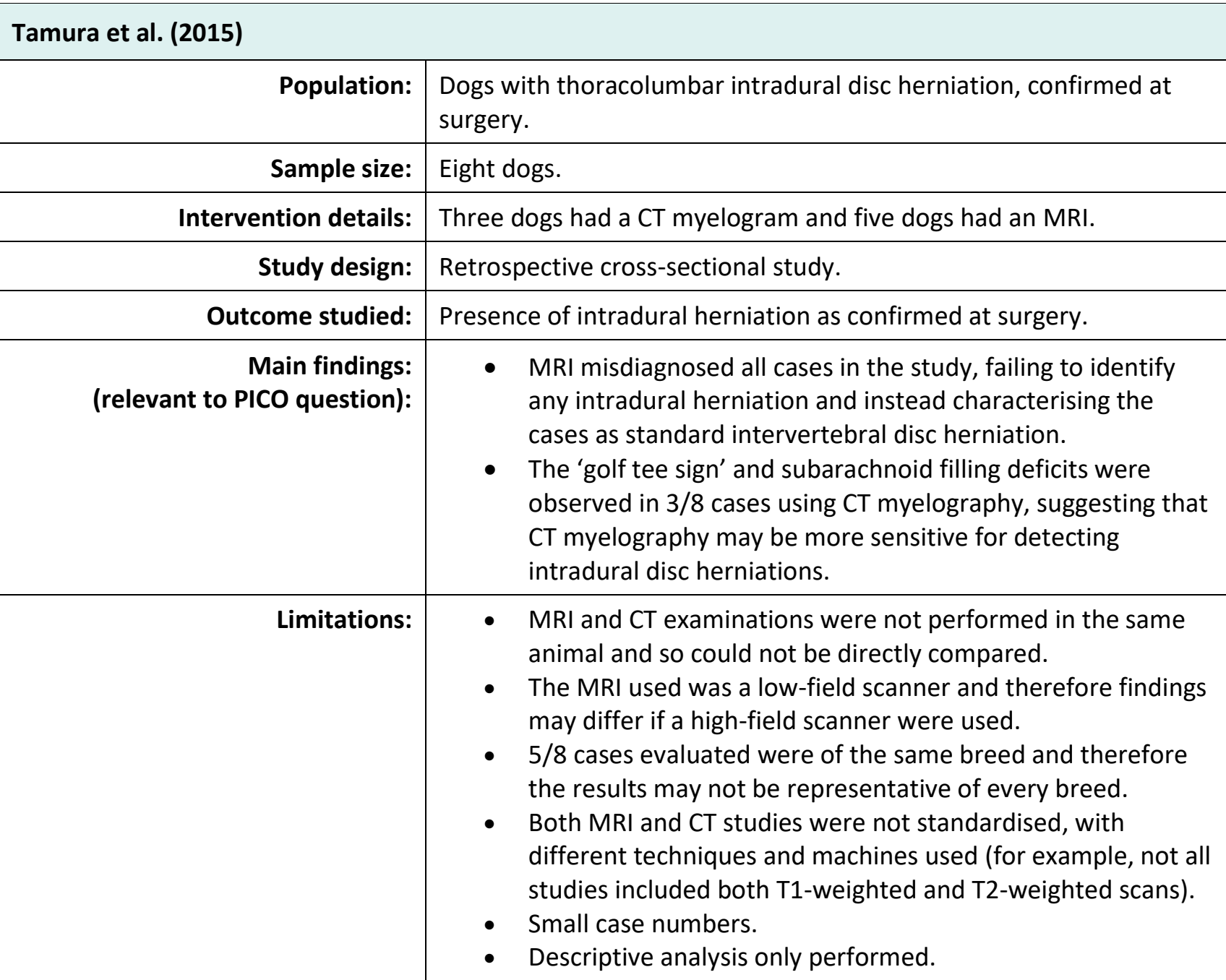

\begin{tabular}{|c|c|}
\hline \\
\hline \multicolumn{2}{|r|}{ Dogs with thoracolumbar myelopathies. } \\
\hline Sample size: & $\begin{array}{l}555 \text { dogs: } \\
\text { - } 450 \text { chondrodystrophic; } 105 \text { non-chondrodystrophic } \\
\text { - } 335 \text { Dachshunds; } 220 \text { other breeds }\end{array}$ \\
\hline Intervention details: & All dogs underwent CT imaging. \\
\hline Study design: & Retrospective cross-sectional study. \\
\hline Outcome studied: & $\begin{array}{l}\text { - The need for additional imaging (beyond thoracolumbar CT) } \\
\text { for the diagnosis of a thoracolumbar myelopathy in dogs. } \\
\text { - Breed, age, sex, chronicity, site of lesion, time of study and } \\
\text { contrast administration. }\end{array}$ \\
\hline $\begin{array}{l}\text { Main findings: } \\
\text { (relevant to PICO question): }\end{array}$ & $\begin{array}{l}\text { Dachshunds were the least likely breed to need additional } \\
\text { imaging (on top of non-contrast CT imaging) with only } \\
\text { 12/335 (3.6\%) of dachshunds requiring further imaging } \\
\text { compared to } 30 / 220 \text { (13.6\%) of other dog breeds. }\end{array}$ \\
\hline
\end{tabular}




\begin{tabular}{|l|l|}
\hline - & $\begin{array}{l}\text { No statistically significant difference was noted in the need } \\
\text { for further imaging when comparing chondrodystrophic to } \\
\text { non-chondrodystrophic breeds. }\end{array}$ \\
- & $\begin{array}{l}\text { The presence of a normal CT, or multiple intervertebral disc } \\
\text { herniations identified on non-contrast CT (and therefore the } \\
\text { difficulty distinguishing acute from chronic lesions) were } \\
\text { both cited as common reasons for requiring additional } \\
\text { imaging techniques. }\end{array}$ \\
- & $\begin{array}{l}42 / 555 \text { (7.6\%) of dogs presenting with a thoracolumbar } \\
\text { myelopathy required further advanced imaging beyond a } \\
\text { plain CT scan. }\end{array}$ \\
Limitations: & $\begin{array}{l}\text { CT scans performed with positive contrast media } \\
\text { intravenously did not alter the need for additional imaging, } \\
\text { compared to those where an intravenous contrast agent was } \\
\text { not used. }\end{array}$ \\
\hline - $\begin{array}{l}\text { The accuracy of lesion localisation and lateralisation was not } \\
\text { assessed in this study and therefore cannot be evaluated. } \\
\text { Retrospective study and therefore no standardisation of } \\
\text { protocols used. } \\
\text { Referral population with patient pre-selection of imaging } \\
\text { modality based on signalment and history. Therefore, not a } \\
\text { true representation of the general case population. }\end{array}$ \\
\hline
\end{tabular}

\begin{tabular}{|c|c|}
\hline \\
\hline \multicolumn{2}{|r|}{$\begin{array}{l}\text { Chondrodystrophic dogs with thoracolumbar intervertebral disc } \\
\text { extrusion. }\end{array}$} \\
\hline Sample size: & 40 dogs. \\
\hline Intervention details: & All dogs underwent CT and MRI. \\
\hline Study design: & Prospective observational study. \\
\hline Outcome studied: & $\begin{array}{l}\text { - Influence of pre-operative planning considerations for } \\
\text { hemilaminectomies based on CT versus MRI. } \\
\text { - Factors studied include; location, lateralisation and extent. }\end{array}$ \\
\hline $\begin{array}{l}\text { Main findings: } \\
\text { (relevant to PICO question): }\end{array}$ & $\begin{array}{l}\text { - Large range in inter-observer agreement for both imaging } \\
\text { modalities (43.5-66.6\%) when assessing the site, side and } \\
\text { size of laminectomy approach. } \\
\text { - All observers planned a larger laminectomy defect based on } \\
\text { MRI compared to CT imaging. } \\
\text { - All lesions were identified in cases when using MRI, however } \\
\text { lesions were not identified in four of these cases when } \\
\text { assessing CT images alone. }\end{array}$ \\
\hline Limitations: & $\begin{array}{l}\text { - Confirmation of imaging findings was not evaluated (e.g. } \\
\text { surgical visualisation of disc herniation). } \\
\text { - No statistics therefore performed to directly compare the } \\
\text { reliability of CT and MRI in detecting lesion localisation. }\end{array}$ \\
\hline
\end{tabular}




\section{Appraisal, application and reflection}

The literature search performed found four papers which addressed, or partially addressed the PICO.

MRI was found to have an increased sensitivity for the detection of intervertebral disc disease in dogs, compared to non-contrast CT (Cooper et al., 2014; and Noyes et al., 2017). However low-field MRI misdiagnosed all cases of thoracolumbar intradural disc herniation when compared with CT myelography in dogs (Tamura et al., 2015).

Non-contrast CT appears to be a sufficient imaging modality for intervertebral disc disease and surgical planning in the majority of Dachshunds (96.4\%; 323/335) (Emery et al., 2018).

Regard for the reason for diagnostics performed (e.g. surgical planning) and the likelihood of other differential diagnoses (e.g. spinal neoplasms) should be taken before deciding to use one imaging modality over the other. Cost, procedure time, and need for a general anaesthetic are also factors that should be considered when assessing between MRI and CT examinations.

\section{Methodology Section}

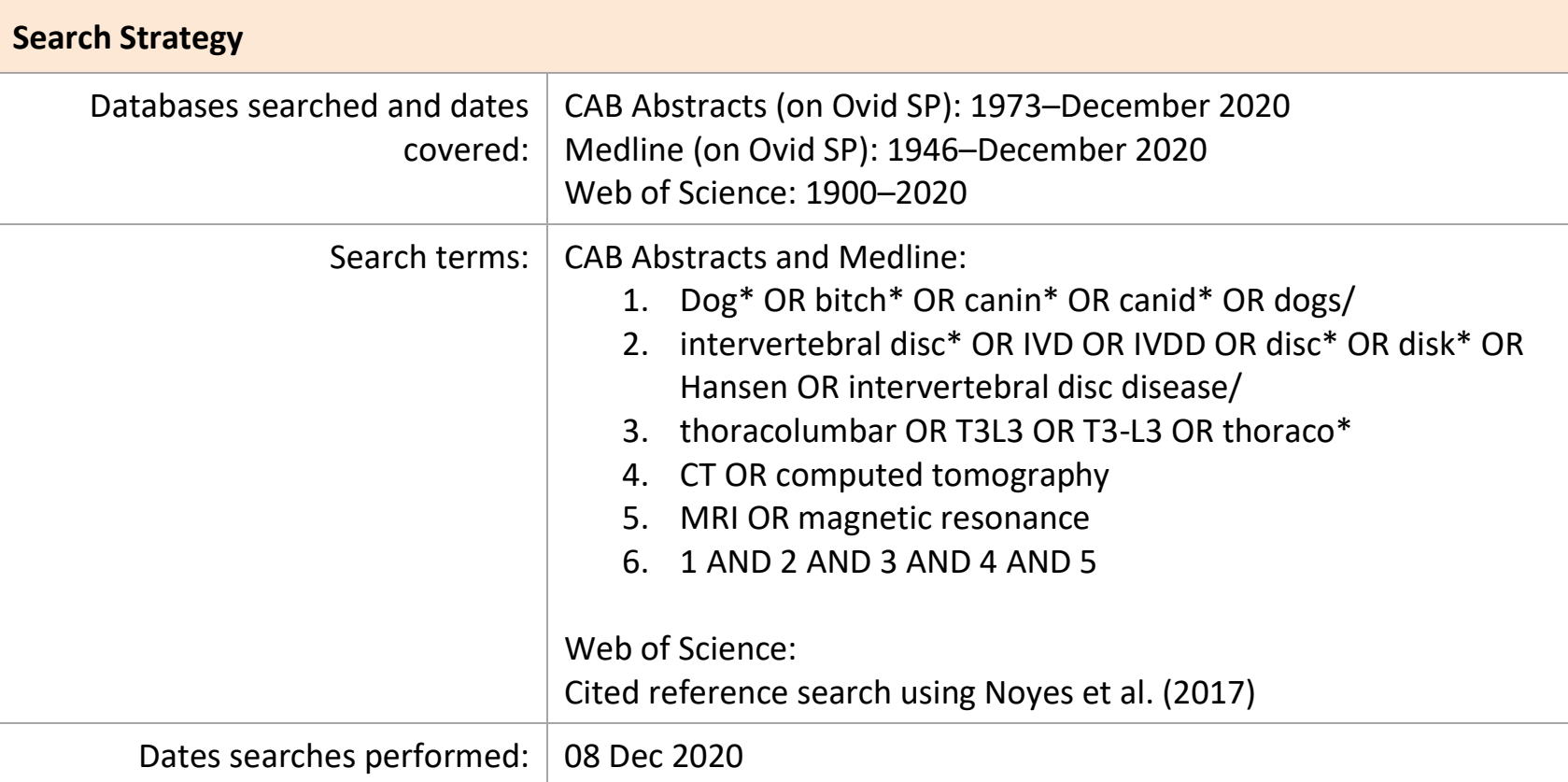

\section{Exclusion / Inclusion Criteria}

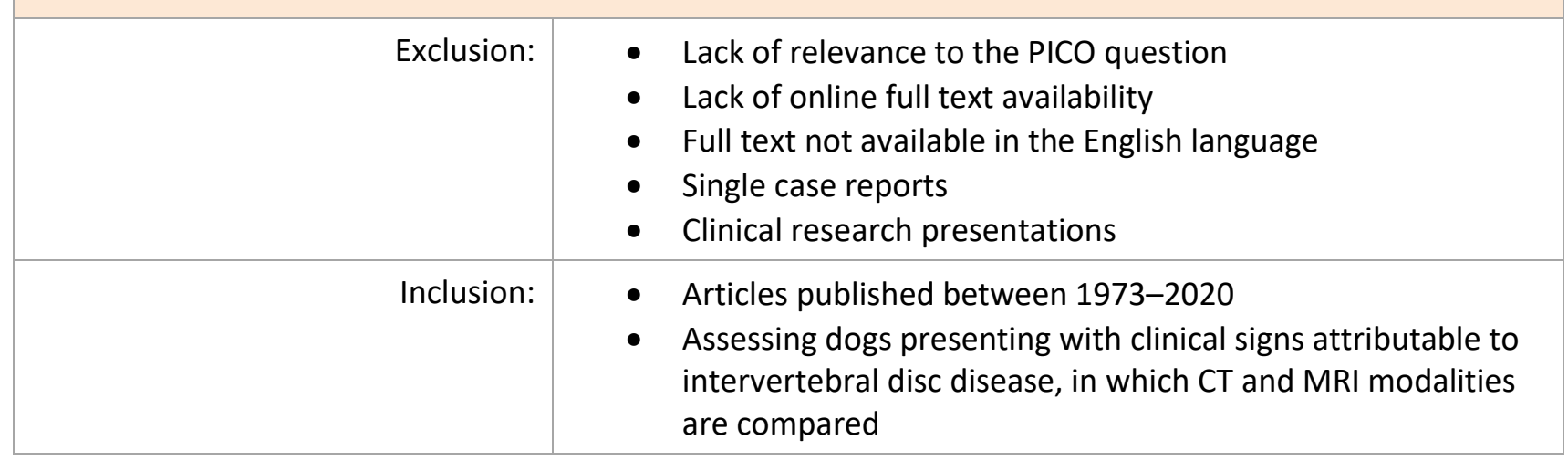




\begin{tabular}{|c|c|c|c|c|}
\hline \multicolumn{5}{|c|}{ Search Outcome } \\
\hline Database & $\begin{array}{l}\text { Number of } \\
\text { results }\end{array}$ & $\begin{array}{l}\text { Excluded - Not } \\
\text { relevant to the PICO }\end{array}$ & $\begin{array}{l}\text { Excluded - Not } \\
\text { available for } \\
\text { review/not available } \\
\text { for review in the } \\
\text { English language }\end{array}$ & $\begin{array}{c}\text { Total relevant } \\
\text { papers }\end{array}$ \\
\hline $\begin{array}{l}\text { CAB } \\
\text { Abstracts }\end{array}$ & 26 & 22 & 0 & 4 \\
\hline Medline & 18 & 14 & 0 & 4 \\
\hline $\begin{array}{l}\text { Web of } \\
\text { Science }\end{array}$ & 30 & 25 & 4 & 1 \\
\hline \multicolumn{4}{|c|}{ Total relevant papers when duplicates removed } & 4 \\
\hline
\end{tabular}

\section{CONFLICT OF INTEREST}

The author declares no conflict of interest.

\section{REFERENCES}

1. Cooper, J.J., Young, B.D., Griffin IV, J.F., Fosgate, G.T. \& Levine, J.M. (2014). Comparison between noncontrast computed tomography and magnetic resonance imaging for detection and characterization of thoracolumbar myelopathy caused by intervertebral disk herniation in dogs. Veterinary Radiology \& Ultrasound. 55(2), 182-189. DOI: http://dx.doi.org/ 10.1111/vru.12114

2. Emery, L., Hecht, S. \& Sun, X. (2018). Investigation of parameters predicting the need for diagnostic imaging beyond computed tomography in the evaluation of dogs with thoracolumbar myelopathy: Retrospective evaluation of 555 dogs. Veterinary Radiology \& Ultrasound. 59(2), 147-154. DOI: https://doi.org/10.1111/vru.12576

3. Noyes, J. A., Thomovsky, S.A., Chen, A.V., Owen, T.J., Fransson, B.A., Carbonneau, K.J. \& Matthew, S.M. (2017). Magnetic resonance imaging versus computed tomography to plan hemilaminectomies in chondrodystrophic dogs with intervertebral disc extrusion. Veterinary Surgery. 46(7), 1025-1031. DOI: https://doi.org/10.1111/vsu.12700

4. Tamura, S., Doi, S., Tamura, Y., Takahashi, K., Enomoto, H., Ozawa, T. \& Uchida, K. (2015).

Thoracolumbar intradural disc herniation in eight dogs: clinical, low-field magnetic resonance imaging, and computed tomographic myelography findings. Veterinary Radiology \& Ultrasound. 56(2), 160-167. DOI: https://doi.org/10.1111/vru.12213 


\section{EVIIDEFeE

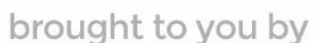 \\ RCVS KNOWLEDGE}

\section{Intellectual Property Rights}

Authors of Knowledge Summaries submitted to RCVS Knowledge for publication will retain copyright in their work, and will be required to grant RCVS Knowledge a non-exclusive license of the rights of copyright in the materials including but not limited to the right to publish, re-

publish, transmit, sell, distribute and otherwise use the materials in all languages and all media throughout the world, and to license or permit others to do so.

\section{Disclaimer}

Knowledge Summaries are a peer-reviewed article type which aims to answer a clinical question based on the best available current evidence. It does not override the responsibility

of the practitioner. Informed decisions should be made by considering such factors as individual clinical expertise and judgement along with patient's circumstances and owners' values. Knowledge Summaries are a resource to help inform and any opinions expressed within the Knowledge Summaries are the author's own and do not necessarily reflect the view of the RCVS Knowledge. Authors are responsible for the accuracy of the content. While the

Editor and Publisher believe that all content herein are in accord with current recommendations and practice at the time of publication, they accept no legal responsibility

for any errors or omissions, and make no warranty, express or implied, with respect to material contained within.

For further information please refer to our Terms of Use.

RCVS Knowledge is the independent charity associated with the Royal College of Veterinary Surgeons (RCVS). Our ambition is to become a global intermediary for evidence based veterinary knowledge by providing access to information

that is of immediate value to practicing veterinary professionals and directly contributes to evidence based clinical decision-making.

\section{https://www.veterinaryevidence.org/}

RCVS Knowledge is a registered Charity No. 230886.

Registered as a Company limited by guarantee in England and Wales No. 598443.

Registered Office: Belgravia House, 62-64 Horseferry Road, London SW1P 2AF

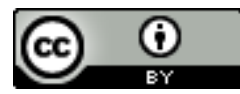

This work is licensed under a Creative Commons Attribution 4.0 International License 